\title{
"The philosophical principles of mathematics" : Elie Cartan, Henri Cartan and Jean Cavailles.
}

\author{
Camille Akmut
}

November 11, 2019

\begin{abstract}
Writings by Elie Cartan and Henri Cartan on Cavailles are presented here, either in a first or new translation.
\end{abstract}




\section{Introduction : $1939-2019$}

Readers will find here translations of two texts by mathematicians Elie Cartan and Henri Cartan; The father was a member of the jury of Cavailles' thesis, the son a "faithful friend" 1

As to Elie Cartan's, we are able to provide the following additional information :

Having created the inventory for the archives of the French Society of Philosophy - the same from which it is drawn - we can say its format is typical of them : a speaker speaks, followed by a group discussion.

Elie Cartan had no qualms about admitting bluntly "I don't understand ... dialectics". One should constantly keep in mind while reading these lines that this was at a time when philosophy still reigned supreme among all disciplines. ${ }^{23}$

He goes on to say he would much rather concentrate on the "purely technical" (!) aspects of his discipline - word for word, he reminds us of a certain class or category of computer scientists and technologists (the mainstream, if not majority).

Jean Cavailles was perhaps the only one in his generation to be able to undertake the type of work he did, argues Henri Cartan. "A philosophical culture and solid mathematical training" he wrote himself. (Though the same applied to Lautman, and probably others.)

Albert Lautman, mentioned regularly, was a friend of Cavailles ${ }^{4}$. They shared many traits : the same type of education, the same area of the philosophy of mathematics, he too a member of the Resistance, killed 5 months after Cavailles...

Many, except one :

Cavailles, we know, was Protestant - an information asserted by Georges Canguilhem multiple times. Why? Presumably as a partial explanation for his ethics, including dedication to his not-only scholarly tasks...

Lautman was Jewish. ${ }^{5}$

\footnotetext{
${ }^{1}$ This is according to a note found in the so-called "Complete works on science". This publication, in fact incomplete, is missing his first article (on the second definition of finite sets by Dedekind) : removed, censored, because it appears they felt that it would shed a bad light on Cavailles - a practice that is the exact opposite of science, in other words. Published by or in cooperation with the CNRS, France's national institution for research...

${ }^{2}$ Convince yourself of this by going further than Cartan senior's contribution. Paul Levy, next up, showed a significantly more subservient attitude : the poor fellow sure had made an effort to make sense of it all... He cannot be blamed. (Him being a former student of the Ecole Polytechnique, an engineer school, rather than the Ecole Normale Superieure (Cavailles, Lautman, Cartan, and co.), a generalist one, must have also been a factor.)

${ }^{3} \mathrm{~A}$ smaller, but nonetheless considerable role is played today by economics, and economists; mathematics is their sword.

${ }^{4}$ In the editor's warning to Transfini et continue (Transfinite and continuous), we learn that the manuscript for it had been given to Lautman, and was only able to be published because his wife had kept it "religiously". (Ibid.)

${ }^{5}$ And, perhaps Canguilhem had Lautman in mind, possibly among others, when he argued - not so adroitly, or smartly - that Cavailles had acted independently from "race" or religion...
} 


\section{From philosophy of mathematics to sociology of computer science}

The writer James Baldwin has famously said : we feel alone until we start reading.

(He had meant the great works of literature ${ }^{6}$.)

History fulfills a similar function; in its own way, with its own means, its own ends - its own limitations too.

Building intellectual models does not proceed of the same sentiment, or in the same fashion as buying meat 'by the pound'.

Cavailles' notions of "accidents of history", let alone "historical contingencies" should leave at least some historians perplexed. (Cavailles : Platonic philosopher, after all?)

Canguilhem's remarks on Marxist interpretations, mass education or "pure" resistance - those we could have done without, and would have rather not have translated, or read. ${ }^{7}$

However none of this makes us forget the extraordinary courage with which they had entered and explored other disciplines, coming from rare backgrounds, delivering uneasy results (e.g. the normal and pathological thesis of Canguilhem ${ }^{8}$ );

fearlessness that had extended far beyond their books, as we know. They moved forward, because they couldn't move backwards.

They showed courage, and gave us courage.

We keep them alive in the only way that we can : by discussing them, and their works - a genuine and sincere attempt to understand them.

In different people we find different things valuable, but needless to say a "dialectic of concepts" we have not undertaken, or attempted...

"The philosophical principles of mathematics", evoked by Elie Cartan in the context of Cavailles and Lautman, are now succeeded by "the social conditions of computer science".

\footnotetext{
6 "[They] taught me that the things that tormented me most were the very things that connected me"... He mentioned Dostoevsky (The Brothers Karamazov) and Dickens.

${ }^{7}$ Although we were already somewhat familiar with Canguilhem's conservative tendencies where certain topics were concerned (e.g. education).

${ }^{8} \mathrm{~A}$ thesis that later became the basis for the normal-abnormal problematic of Foucault.
} 
Elie Cartan :

I'm a bit embarrassed, I have to say, being in this situation somewhat like Mr. Jourdain, who spoke in prose without knowing it.

Mathematicians - at least a number of them, of whom I would consider myself one - are little used to thinking about the philosophical principles of their science.

When they hear a philosopher talk about their discipline, it interests them, no doubt, but they don't really know how to respond to the ideas that they develop.

Of course I know Mr. Cavailles' thesis and Mr. Lautman's, having been a member of the jury of both, but my situation is different : previously I was on the right side of the barricade, whereas today, I'm on the other...

I have not quite understood what opposition existed between both viewpoints; it seems to me that they are different rather than opposed.

My feeling is that the ideas of Mr. Cavailles relate to the very foundations of mathematical thought, whereas Mr. Lautman has focused on the current state, not of the whole of mathematics, but a certain number of mathematical theories; and, in this regard, it is obvious that a certain number of Mr. Lautman's propositions are of particular interest to me : the ones pertaining to the relationships between the local and the global, for example.

Without a doubt these relationships are relevant for an important part of mathematics. The theory of functions, in particular that of functions of real variables, as we have conceived of it for 50 years, is unable to face this issue of the global and local; its functions are too general for us to be able to deduce global properties from local ones;

as for quasi-analytic functions [quasi-analytiques], which have been introduced recently, something analogous happens : once we know in one point the values of the function and those of its successive derivatives, it [the function?] is completely defined in its entire field of existence.

In geometry - it was primarily geometry that Mr. Lautman had in mind - one also finds extremely important problems that can be thought in terms of this relationship between the global and local : if we take for example, inside a space, a small portion of that space, can we then deduce from the knowledge of this small piece a general knowledge of the entire space? It is understood that we must assume the global properties simple enough, without which this problem would not make sense.

These are, superficially, pure problems of geometry; in reality, they are also problems of analysis. Let us take a portion of Riemann space : if you assume that the functions involved in defining this space are analytic ones, you'll soon be faced with an extremely interesting problem, which is the following : knowing one small piece of Riemann space, defined analytically through its differential form, up to which point [how far] can we deduce the global properties of this space?

This small piece may not be enough to be extended to form a complete space; in general, this is what happens. If it can be extended to form a full space, it can only be in one way, and with certain restrictions. 
There you have it, a problem of the relationships between global and local which is not defined simply through geometric formulation [enunciation], but which is linked to the existence of purely analytic properties in the definition of that piece of space.

One could develop analogous considerations with regard to the relationships between the intrinsic and extrinsic. Given a surface inside a space, do the intrinsic properties - assumed known - of the surface lead to limitations of the properties of the space which contains it? There are here extremely interesting problems; but we should note that they depend not only on the geometric situation [position] of the problem, but on its analytic one.

Mr. Lautman has given a certain number of other examples of such problems : form and matter; group theory [the theory of groups].

All this is very interesting, but I don't know to what degree it supports the general thesis of Mr. Lautman, because I don't understand what dialectics are very well, and I need to remain on a purely technical ground [terrain]

I don't feel that that the considerations of Mr. Lautman are in conflict with those of Mr. Cavailles. My impression being that Mr. Lautman has considered certain specific problems of current mathematics, and a certain number of philosophical ones. On the whole, I believe myself to be in agreement with him, but unfortunately I'm unable to debate him on that level.

In any case, as to the development of mathematics being autonomous and unpredictable, I don't think that we can contradict this proposition. However history teaches us that that the history of mathematics - which I have myself lived and known - has had moments of premonitions [previsions d'avenir] [predictions] : in 1900, a conference by Hilbert of the future problems of mathematics took place, a remarkable one, in which many of the problems that would preoccupy mathematics for the next 50 years had been laid down; and he had predicted exactly the kind of problems which in fact were the problems of mathematics to come.

On the other hand, one could name a many conference by prominent scientists, from various disciplines, whose predictions were a total dud.

Certainly there is something unpredictable about the development of mathematics, and when reaching a certain age, one notices how over the course of 20 or 30 years some theories have taken completely unexpected turns; and that the point of view from which they had originally been considered has become a totally different one. These are internal necessities, one must admit, that are later revealed. I'm thinking of topology, for instance, this science which barely existed 50 years ago and now permeates all other branches of mathematics.

Paul Levy : ... I'm a bit disconcerted to hear philosophers talk about the science that I know, in terms that are totally foreign to me. I'm not sure I understand what they're saying (...)

[This debate took place in 1939] 


\section{Henri Cartan :}

It has been over 40 years since Cavailles wrote his work Axiomatic method and formalism [Methode axiomatique et formalisme]. Since then logic has changed a lot, while, on its side, mathematics has known spectacular and often unpredictable developments, both due to the introduction of new concepts and the solutions given to problems long unsolved (the former often helped to solve the latter).

However, the reflections of the young Cavailles of 1937 have lost none of their relevance today : they help us gain access to a period in the evolution of mathematical ideas rich in controversies. Cavailles was perhaps the only one, then, able to undertake such a work...

$(\ldots)$

[1981] 


\section{References}

1. Cavailles, Jean and Lautman, Albert. 1946. "La pensee mathematique" [Mathematical thought]. 1946. Bulletin de la Societe francaise de Philosophie XL. (Session February 4th, 1939).

2. Cavailles, Jean. 1981. Methode axiomatique et formalisme [Axiomatic method and formalism]. 2nd ed.. 